\title{
The use of image and laser scanner survey archives for cultural heritage 3D modelling and change analysis
}

\author{
Gabriella Caroti ${ }^{1}$, Isabel Martínez-Espejo Zaragoza ${ }^{1}$, Andrea Piemonte ${ }^{1}$ \\ ${ }^{1}$ Civil and Industrial Engineering Department (DICI)/University of Pisa, Largo Lucio Lazzarino 1, 56122 Pisa, Italy
}

\begin{abstract}
Cultural heritage studies often require the analysis of buildings that have undergone several changes and alterations during their lifetime. This often implies the loss of architectural elements or the construction of new elements, which both change the characteristics of the former buildings. The recovery of lost elements or structures through virtual reconstruction is of paramount importance in both scientific and cultural applications. Novel procedures in surveying and photogrammetric processing including historical photogrammetry and historical terrestrial laser scanning offer powerful tools that enable the extraction of geometric information from historical documentation such as archival images. This paper presents the integration of a metric 3D model with information present in archival surveys of lost architectural volumes. The methodology implies the availability of historical plans representing the survey object at scales consistent with UAV surveys and featuring shared elements. The methodology used to frame these plans in the reference system of the UAV survey for an open source GIS environment is also described as well as the accuracy checks. Finally, the procedure followed for the virtual reconstruction of the Fortezza in a BIM environment, which produced a model derived from the integration of historic and current data, is described.
\end{abstract}

\section{Section: RESEARCH PAPER}

Keywords: Cultural heritage; photogrammetry; laser scanner; BIM

Citation: Isabel Martinez Espejo Zaragoza, Gabriella Caroti, Andrea Piemonte, The use of image and laser scanner survey archives for cultural heritage 3D modelling and change analysis, Acta IMEKO, vol. 10, no. 1, article 15, March 2021, identifier: IMEKO-ACTA-10 (2021)-01-15

Section Editor: Carlo Carobbi, University of Florence, Italy

Received April 30, 2020; In final form August 24, 2020; Published March 2021

Copyright: This is an open-access article distributed under the terms of the Creative Commons Attribution 3.0 License, which permits unrestricted use, distribution, and reproduction in any medium, provided the original author and source are credited.

Funding: This work was partially funded by PRA 2017/12 University of Pisa Project

Corresponding author: Isabel Martínez-Espejo Zaragoza, e-mail: isabel.zaragoza@unipi.it

\section{INTRODUCTION}

Surveying and documenting cultural heritage is essential for its protection and sustainable management [1].

In the last decades, new instruments and innovative surveying methodologies have brought fresh data and insights to the field of cultural heritage. These methodologies are at once innovative, simplified, user-friendly and challenging for researchers.

In addition to an understanding of the methodologies and techniques, these investigations require the full knowledge of a cultural heritage object, including its original concept, the timeline of any modification, its current conditions, the causes of the decay and their historical contextualisation, etc.

For this purpose, surveys provide valuable support in the investigation of historical sources, whether bibliographical, documental or iconographical, and can help in maintaining the consistency of geometry, materials and build.
Photogrammetry methodologies play a prominent role due to the availability of a vast array of both historical and current photographical images of cultural heritage.

Such an array is of foremost importance, as it provides information that is valuable for preliminary investigations, e.g. evidence of past interventions that are difficult to trace or a presentation of a building's current condition [2].

Historical photogrammetry (HP) has been used in several cultural heritage investigations in order to assess whether additional information can be provided by referring these images to new 3D survey models and to evaluate the potential offered by this kind of operation [3]-[8].

Laser scanning, both terrestrial and airborne, is possibly the most important surveying technology developed over the last 20 years. In this time span, its use as a means of producing dense point clouds for documenting, mapping and multi-scale viewing purposes has evolved, and it is now a standard approach [9]-[12]. Moreover, classical photogrammetry is regularly integrated with other types of geomatic investigation. 
The use of laser scanning in cultural heritage surveying and documenting for over 20 years has in turn led to a large archive of real-scale dense point clouds, which provides support for architectural research and historical cataloguing and makes it possible to perform multi-temporal comparisons and investigations.

As with HP, data processing methodologies for historical terrestrial laser scanning (HTLS) also present some difficulties. First, HTLS data usually come in proprietary formats, which are not readily convertible to current standards. In addition, several HTLS data sets only provide 3D coordinates and reflectance values and lack any colour information, which can pose additional problems during manual point registration, which is necessary in cases where the cloud-matching algorithms are unsuccessful, e.g. due to insufficient overlap between adjacent scans. The lack of colour information could further complicate the detection of tie points for the orientation of historical images.

Finally, the density and precision of HTLS clouds reflect the technological limitations of the time periods in which the original images were created.

The aim of the current study is to define a methodology for the recovery of HTLS and HP data in order to generate 3D models of survey objects to support multi-temporal investigations of the geometry of objects that have been subjected to alterations, modifications and changes of use over time.

The investigation focused on two case studies: a section of the medieval urban walls by Porta San Zeno (St. Zeno's Gate) in Pisa and the Fortezza Vecchia (Old Fortress) site in Livorno, Italy. Porta San Zeno underwent major restoration and improvement activities starting in 2012. Preliminary surveys, however, started in 2010 and provided historical TLS, photogrammetry and photographic data that was used for the present investigation. More recent photographic data reporting the results of the restoration and improvement interventions was also used. The Fortezza Vecchia suffered several volume losses due to restoration interventions both during and after World War II. In this case, archive images were used to create a metric $3 \mathrm{D}$ reconstruction of the Palazzo di Cosimo De' Medici.

\section{MATERIALS}

\subsection{Urban walls in Pisa}

Porta San Zeno, one of the medieval gates that provided access to the city of Pisa, is located near its namesake church (Figure 1, top). Its current setting dates back to 1935 , when it was reopened in order to alleviate urban vehicular traffic by providing a route towards SS12 and SP2 (Via del Brennero and Via Calcesana). The defensive complex includes a round arch complemented by a lowered arch curtain built in Verruca stone, following the Pisa custom, and supported by rectangular pillars, also in Verruca stone, topped with plain capitals. In the intrados, the stone rings, which originally provided support for the gates' hinges, are still visible.

The face in which the arch is set is made of Asciano breccia that has been neatly cut into rectangular ashlars. It was built between 1156 and 1158 as a closure for a wall section joining two existing sections along the north-east direction by St. Zeno's Abbey.

The wall section including the gate was later involved in the reinforcement of urban defences following the defeat suffered by Pisa in the battle of the Meloria in 1284. During this time, the wall was widened and a moat was dug along its outer side.
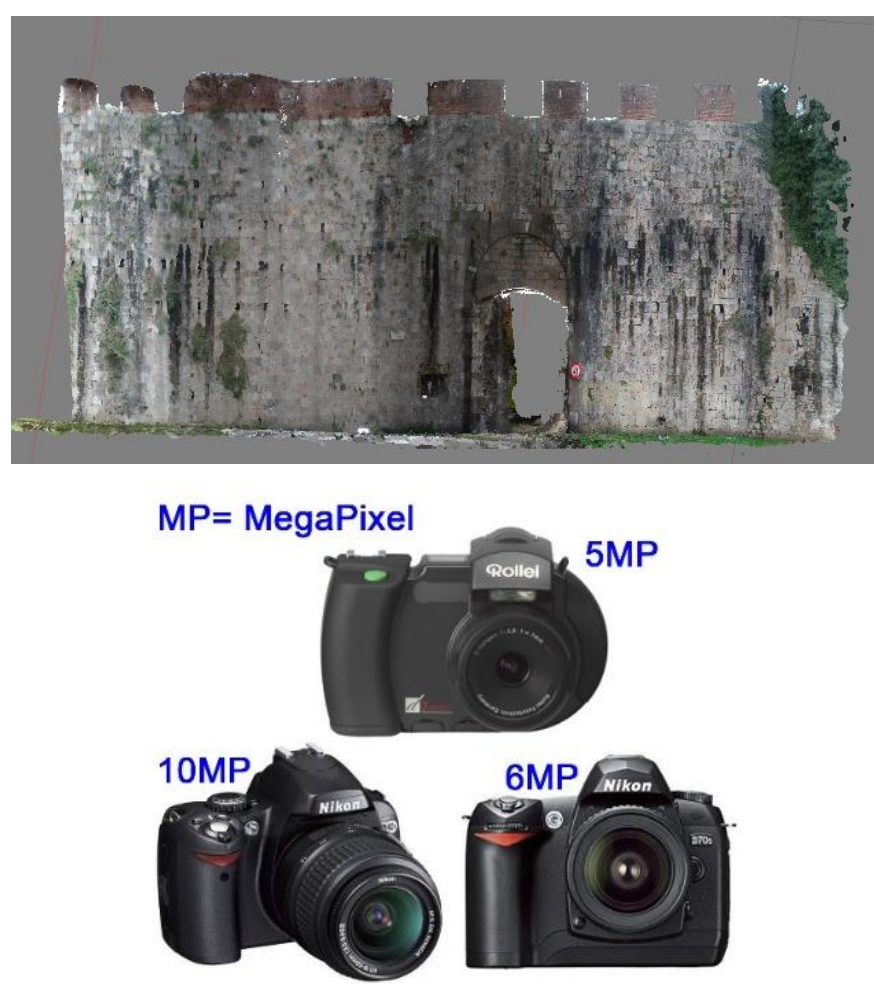

Figure 1. Photogrammetric point cloud from historic images (top) and cameras used for collecting historic images (bottom).

The section of urban walls between the Gates of Lucca and St. Zeno retains its original inner and outer brackets [13].

\subsubsection{0 survey campaign}

In 2010, ASTRO laboratory carried out a surveying campaign in order to document the current status of the wall sections around the gate. The surveys employed two different techniques: a TLS survey using a Riegl LMS-Z420i laser scanner and a photogrammetric survey using both a semi-metric Rollei d7 digital camera and an amateur digital Nikon D40X camera (Figure 1, bottom).

The Riegl LMS-Z420i laser scanner automatically associates laser scans with high-resolution images collected by a calibrated camera installed in a dedicated socket on top of the device. It has a precision of $10 \mathrm{~mm}$ in up to a $50 \mathrm{~m}$ range $(1 \sigma @ 50 \mathrm{~m}$ range under Riegl's test conditions). The integrated camera used in the survey was a Nikon D70 (Figure 1, bottom) digital camera fitted with a fixed focus $(f=20 \mathrm{~mm})$ lens, whose other features included a $6.1 \mathrm{MP}, \quad 23.7 \times 15.6 \mathrm{~mm}^{2}$ sensor and a 2000 px $\times 3008$ px image size.

The Rollei d7, which was used in the photogrammetry survey, had a $28 \mathrm{~mm}$ fixed focus $(f=7 \mathrm{~mm}, 1: 2.8)$ lens on a $35 \mathrm{~mm}$ camera with a $5 \mathrm{MP}, 8.8 \times 6.6 \mathrm{~mm}$ sensor and a $2552 \mathrm{px} \times 1920 \mathrm{px}$ image size. The Nikon D40X had a variable focus $(f=18-55 \mathrm{~mm})$ lens, a $10.2 \mathrm{MP}, 23.6 \times 15.8 \mathrm{~mm}^{2}$ sensor and a $3872 \mathrm{px} \times 2592 \mathrm{px}$ image size.

These images were intended for photographic straightening and therefore have no or very poor mutual overlap. Since no photogrammetric modelling was planned, the focal length was also inconsistent between images collected with the Nikon D40X camera. The Nikon D70 also collected some context images of the Arch as supporting documentation.

\subsubsection{9 survey campaign}



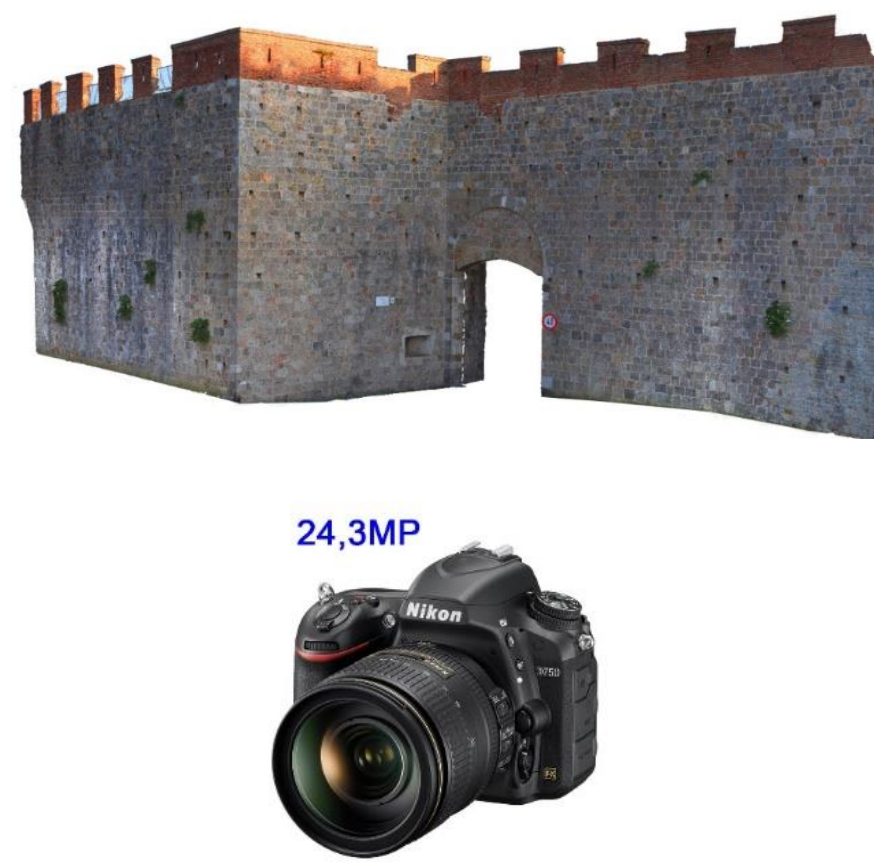

Figure 2. (Top) Photogrammetric model from 2019 survey. (Bottom) Nikon D750 camera.

The 2019 survey campaign carried out by ASTRO laboratory integrated TLS with structure from motion (SfM)- and multiview stereo (MVS)-based photogrammetry (Figure 2, top).

The instrument used for the TLS survey was a Leica C10 ScanStation with sub-centimetre precision and an on-board camera.

Photographs were collected by a Nikon D750 digital camera (Figure 2, bottom) fitted with a fixed focus $(f=50 \mathrm{~mm})$ lens at an average range of about $10 \mathrm{~m}$, resulting in a ground sampling distance of about $1.2 \mathrm{~mm}$.

A topographical survey performed with a Leica TCRP 1201+ total station provided the coordinates of the ground control points (GCPs) and therefore a shared reference system for TLS and photogrammetry, as well as the ability to scale the latter.

\subsection{The Fortezza Vecchia}

The Fortezza Vecchia in Livorno, Tuscany, is the last of an array of fortifications designed by architects Giuliano and Antonio da Sangallo between 1488 and 1519, with which they experimented and improved upon the modern outline of fortifications with corner bastions. The Fortezza Vecchia complex included a preexisting fortification, known as Quadratura dei Pisani, that was built around the second half of the $14^{\text {th }}$ century to strengthen an existing medieval keep. Pre-existing structures as well as the site itself, which is surrounded by the sea, deeply affected the building process, resulting in several anomalies and departures from the ideal regular form pursued by Renaissance military architecture [14].

\subsubsection{Archive documentation}

Historic documents referring to Fortezza Vecchia include a set of plans dating from 1669 to 1676 [15] that show the interior layout and the design of public and residential spaces. A further set of plans, dating from the $18^{\text {th }}$ to the $20^{\text {th }}$ century tracks multiple changes in the intended use of the complex after it ceased to serve as a military fortress [16].
Photographs predating WWII show the size of the complex and the huge barracks located in the large squares of the fortress. Early $20^{\text {th }}$ century images mostly show global views of the complex.

Both the $18^{\text {th }}$ and $19^{\text {th }}$ century plans and the $20^{\text {th }}$ century images record ongoing construction constraints due to lack of space.

\subsubsection{Current survey}

The ASTRO laboratory status quo reference survey was made available by the North Tyrrhenian Sea Port System Authority within the framework of the 2017 PRA research project 'Tuscany's renaissance architectures: case studies between historical investigation, survey and structural analysis', funded by the University of Pisa.

This survey of the fortress was based on UAV-borne imagery, which enabled the reconstruction of a 3D model of the exterior. In addition, the UAV-borne imagery was used to detect homologous points for the orientation of archive images based on unchanged architectural details.

A fixed focus ( $f=20 \mathrm{~mm}-35 \mathrm{~mm}$ format equivalent) camera with a 12.4 MP (image size $4000 \mathrm{px} \times 3000 \mathrm{px}$ ) 1/2.3" CMOS sensor set onto a DJI FC330 UAV was used to collect a total of 110 images, which were divided into two sets based on their flight levels relative to the top of the walls $(40 \mathrm{~m}$ and $60 \mathrm{~m}$ ).

\section{METHODS AND RESULTS}

\subsection{Urban walls in Pisa}

The data sets described above yielded two models. In the first case, all of the images collected by the cameras in the 2010 survey were processed using SfM and MVS to generate a 3D photogrammetric model (Figure 1, top). Orientation with automatic tie-point detection was successfully performed on 77 out of 92 images collected with the three cameras. The photogrammetric alignment for this model presented some problems due to both different image resolutions and quality and insufficient overlap, since the photographs were intended for the production of photoplans. In addition, the model has poorly defined sections and minor morphological issues resulting from variable focal lengths, pixel (px) sizes and image sizes. For these reasons, manual input was required for about 35 tie points in order to assist the photogrammetry software in correctly matching homologous points. The precision of the resulting model was assessed using check points (CPs), the coordinates of which were derived from the TLS survey.

TLS provided the coordinates of some of the GCPs used for the photogrammetric processing (8 points). Selecting another 10 control points for alignment checking yielded a mean error of $2.8 \mathrm{px} / 5 \mathrm{~cm}$.

This model represents the survey object prior to any restoration intervention, showing the volumes and the decay.

The 2019 survey generated a further high-precision photogrammetry model, representing the survey object after the restoration (Figure 2, top).

The comparison between these models provides important documentation of the changes and makes it possible to analyse variations in volumes and geometry and determine the impact of the restoration and the extant of structural decay.

The 2010 model reveals several pathologies, such as the lack of crowning on the majority of the battlement, geometric disruptions and fractures and the presence of biotic film and 


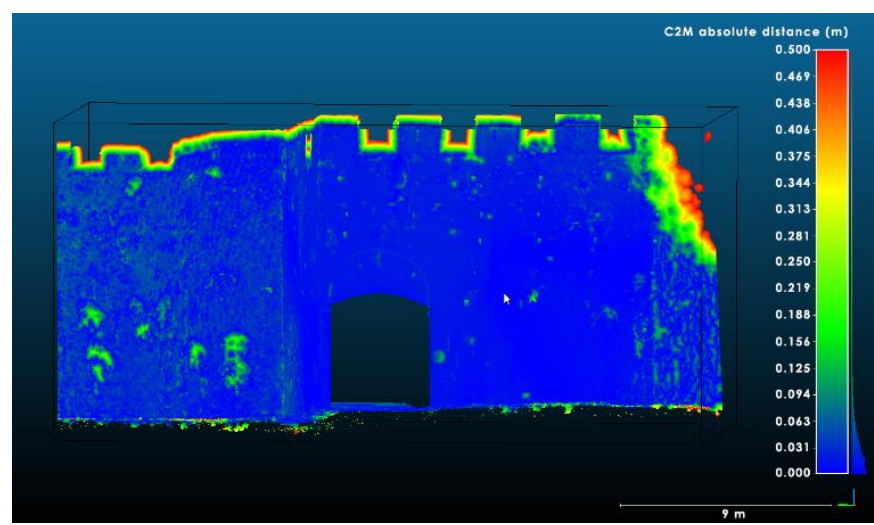

Figure 3. Comparison between 2010 and 2019 photogrammetric models.

shrubs growing on the walls, breaking up the building materials and affecting the optimal structural conditions.

Moreover, the 2019 model makes it possible to track the geometrical changes that have accrued over time, such as the integration of volumes that modified previous shapes and the addition of external elements allowing for safe pedestrian movement. The removal of biotic film and the restoration of fractures can also be observed, along with the ongoing growth of shrubs and other plants continuing their disruptive action on joints.

The two clouds have been compared in order to visually detect the morphological changes that have occurred over time (Figure 3).

\subsection{The Fortezza Vecchia}

After the Second World War, the Palazzo di Cosimo was razed in some areas, while in others the walls suffered partial damage. A virtual reconstruction of the building using building information modelling (BIM) software, in this case Revit, was made to enable the study and historical documentation of these changes. The reference period for the reconstruction is the early 20 th century, before the war and the partial destruction of the building. Historical archive photographs that date back to this period are available.

The virtual reconstruction is based on three key elements: ancient plans designed in the 18th century, photographs taken between the late 1800s and the early 1900s and the 3D model of the current situation obtained by the photogrammetric processing of airborne imagery.

\subsubsection{Measures obtained from the historic plans}

The 18th century plans of the Palazzo were scanned at a resolution of $300 \mathrm{dpi} \quad(6370 \mathrm{px} \times 4632 \mathrm{px}$ and $\left.53.93 \times 39.22 \mathrm{~cm}^{2}\right)$. The image included a graphic scale indicated on the Florentine coat of arms. In order to define the scale of the representation and therefore the real size of a single pixel, some linear measurements obtained from the historical plan were compared with those obtained from the photogrammetric model. From this comparison, it was determined that a pixel corresponds to a size of about $2 \mathrm{~cm}$. A new graphic scale in metres was therefore inserted onto the image (Figure 4).

In order to be able to use these scans in the definition of the 3D model, it was necessary to georeference them and to minimise deformation errors as much as possible.

Georeferencing of the historical plan was performed in the QGIS environment using a first-degree polynomial geometric transformation, upon which it was resampled using the nearest neighbour algorithm.

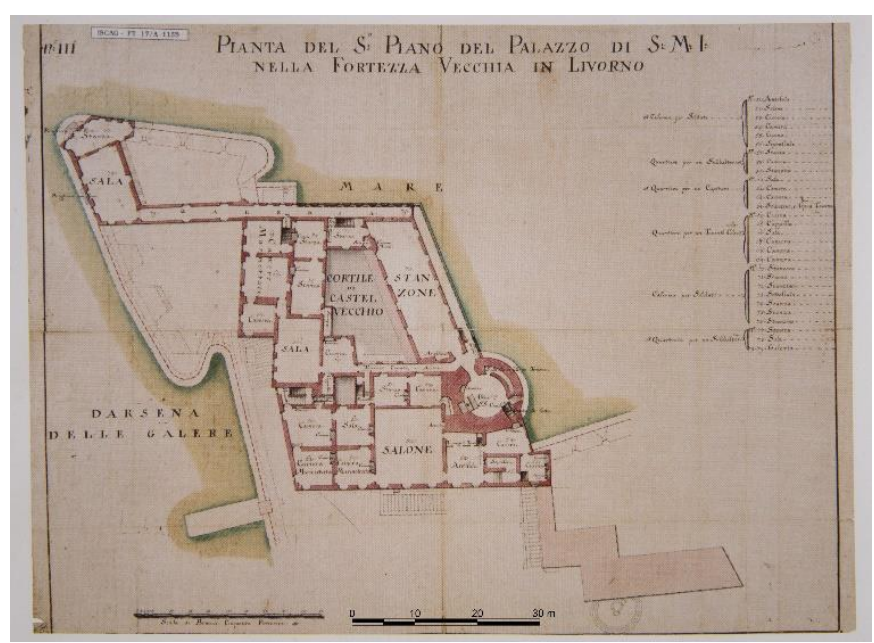

Figure 4. Eighteenth century plan of the Palazzo di Cosimo.

To determine the transformation parameters, ten recognisable points were identified both in the paper plan and in the orthophotograph obtained from the photogrammetric survey (Figure 5).

Six of these points were used as GCPs to calculate the transformation parameters, and four were used as CPs.

The residuals for the GCPs, which give an indication of the accuracy, were on average 42 pixels, while the residuals for the CPs, which indicate precision, were on average 45 pixels. These results agree in terms of their order of magnitude, indicating that the solution provided is acceptable for the transformation. As stated above, the scanned plan's pixel size in metric units is equal to about $2 \mathrm{~cm}$, so, based on the mean pixel error, the plan is accurate to within $84 \mathrm{~cm}$ and precise to within $90 \mathrm{~cm}$.

Considering this type of historical plan, its state of conservation and the deformations that the support may have had over time as well as the graphical and metrical accuracy of the archive surveys, the authors believe that the achieved results of the transformation were adequate for the subsequent work of integrating and verifying the data obtained from the photogrammetric processing of the archival images.

\subsubsection{D points definition through historical images}

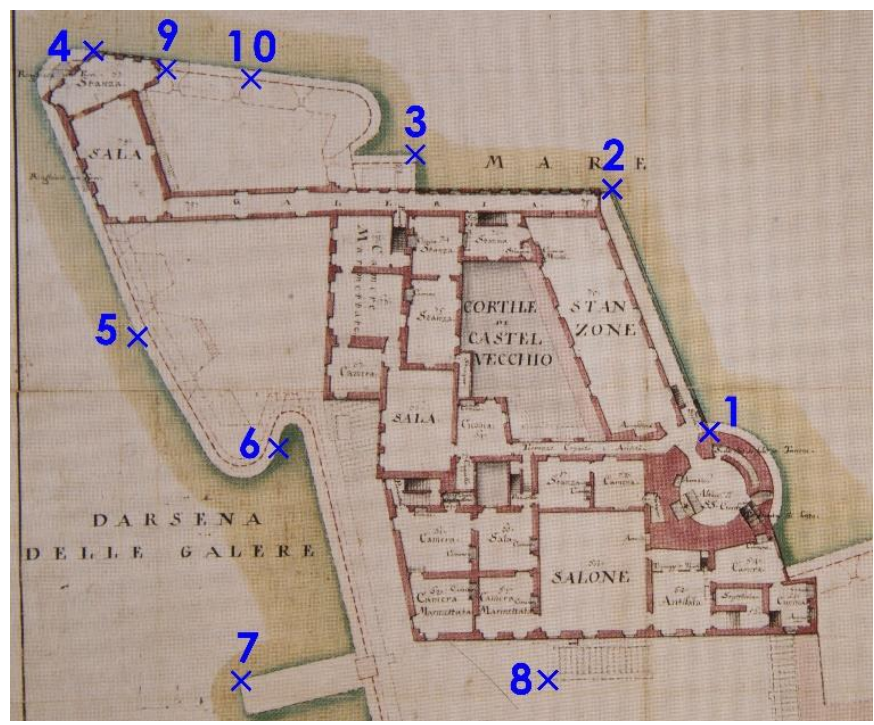

Figure 5. GCPs and CPs on 18th century plan. 

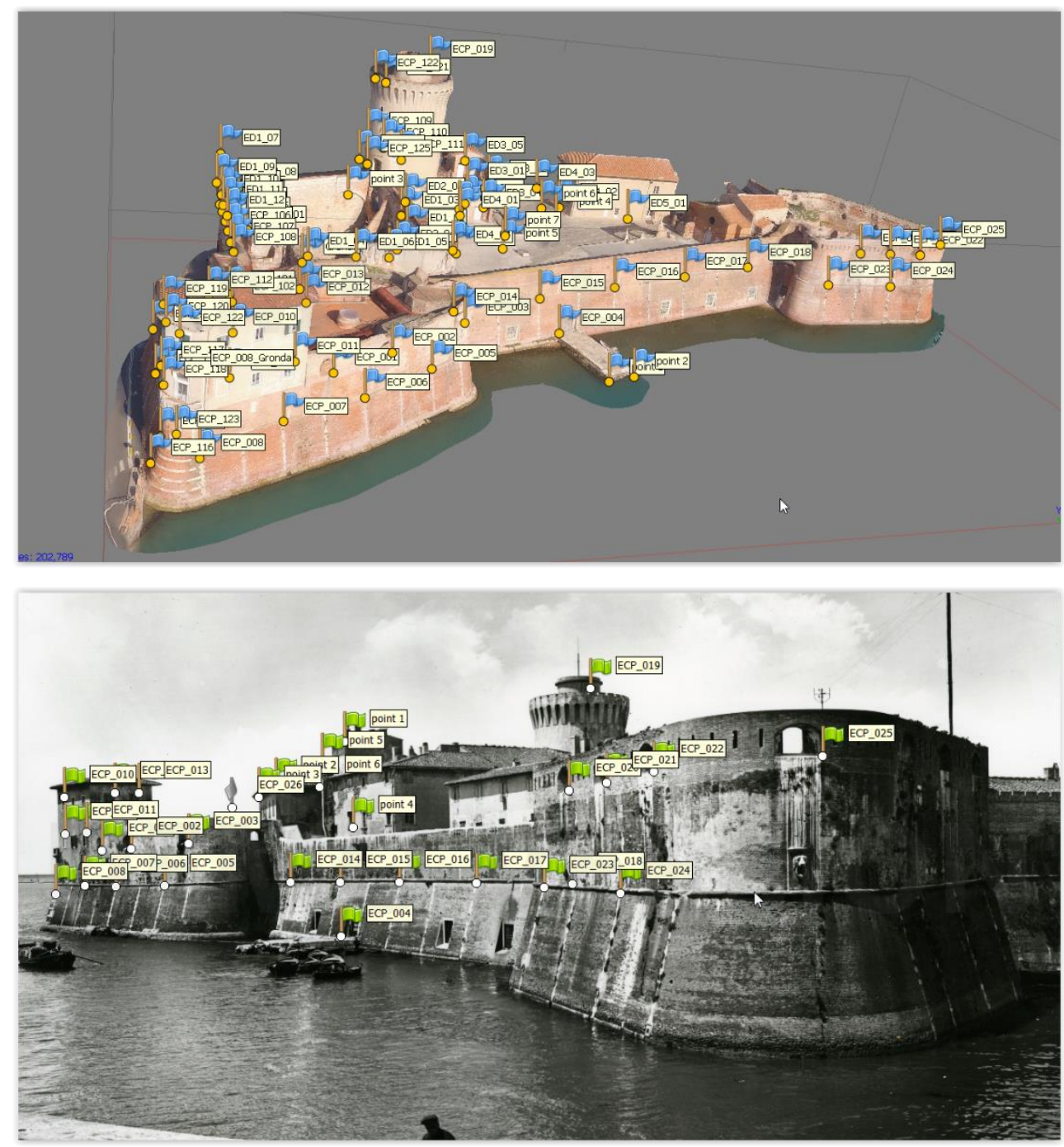

Figure 6. Tie points on the 3D model (top) and on the archival image (bottom)

In this case, the images had not been collected by digital cameras with known features; instead, analogue archival images were used.

Processing analogue photographs, especially older ones, is more complex than processing digital ones due to the quality of the photographs as well as issues related to digitisation and technical equipment. However, it is even more difficult to process materials that were produced from different sources of uncertain origin and unknown parameters, especially if those images are of poor quality and include deformations [4].

When using archival images, much of the information that is needed for correct photogrammetric processing is lacking, so it is not possible to achieve homogeneous geometric precision or generate complete 3D models. Nevertheless, in the case of the Fortezza Vecchia, it was possible to reconstruct lost volumes. For this purpose, however, in addition to strictly following geomatics guidelines, an in-depth historic-architectural investigation of the study object was required to fully comprehend and better exploit the available images.

While the photogrammetric processing of these images did not allow for automated point cloud generation, it did provide geometric references for subsequent processing. Points can be measured in separate images and subsequently calculated by ray intersection using orientation parameters calculated by bundle adjustment. Although seemingly straightforward, this step in fact poses some practical issues. Due to differences in image scale, radiometric and geometric resolution, shooting position, lighting conditions, etc., it is often quite difficult to detect the same point in two different images. Coordinate precision for the resulting points is related to the lower precision of pairs of image coordinates and the conditions of ray intersections [17].

The photogrammetry project included the set of UAV-borne images and five archival images dating to the 1930s. As already stated, the different features of the archive images and their shooting geometry, as well as major scene modifications, prevented the automatic detection of tie points, which were therefore detected manually. This was carried out with the following steps:

1) areas that have not changed or undergone major restoration since the 1930 s were selected based on historical research;

2) architectural elements within these areas were surveyed in order to keep sighting errors on the images as low as possible;

3) points providing the most homogeneous layout were identified on both the images and the 3D model.

A total of 52 points were selected and sighted (Figure 6, top). Half of the points were on images collected along the northsouth direction and half were on images collected in the eastwest direction. The large number of points was necessary for 
bundle adjustment in order to reduce sighting errors caused by the poor resolution of the archival images as much as possible.

A further 20 control points were selected for alignment checking. A comparison of the 3D coordinates of the CPs with those of the photogrammetric model resulted in a mean error of $1.3 \mathrm{px} / 12 \mathrm{~cm}$.

The integration of the UAV-derived 3D model of the fortress with on-site analysis made it possible to outline the main walls of some buildings, such as those bounding the Cortile del Castello $V$ ecchio, while other areas, particularly on the west and south sides, were not so well-defined.

Identifying the points from the archive images (Figure 6, bottom) in the UAV-derived 3D model yielded the external outline of the south and west perimeter walls as well as most eaves and some window sills.

The easiest way to obtain the 3D model of the vertical walls would have been using photogrammetry starting from ancient photos. A similar method was used in modelling Porta San Zeno. However, as previously stated, it was not possible to automatically obtain a dense point cloud from these images due to poor image quality and resolution. Since the orientation parameters of these images were known, it was instead possible to use them to obtain the 3D coordinates of significant points (windows, doors, wall heights, etc.).

Those 3D coordinates were then exported to a CAD environment and subsequently to Revit.

Historical photogrammetry, therefore, makes it possible to obtain metric information that is unavailable in other graphic archival documentation. These findings enabled the creation of a $2 \mathrm{D}$ outline for the entire complex, which is in turn essential for subsequent $3 \mathrm{D}$ reconstruction. Calculated elevations of lost buildings along with numerical information from historical documents provide a useful support for a possible reconstruction of the interior that could also take advantage of extant building portions (Figure 7).

\subsubsection{D virtual reconstruction}

The Palazzo di Cosimo de' Medici was partially reconstructed using Autodesk's Revit BIM software. For this purpose, the first step involved using Autodesk's ReCap software to export the

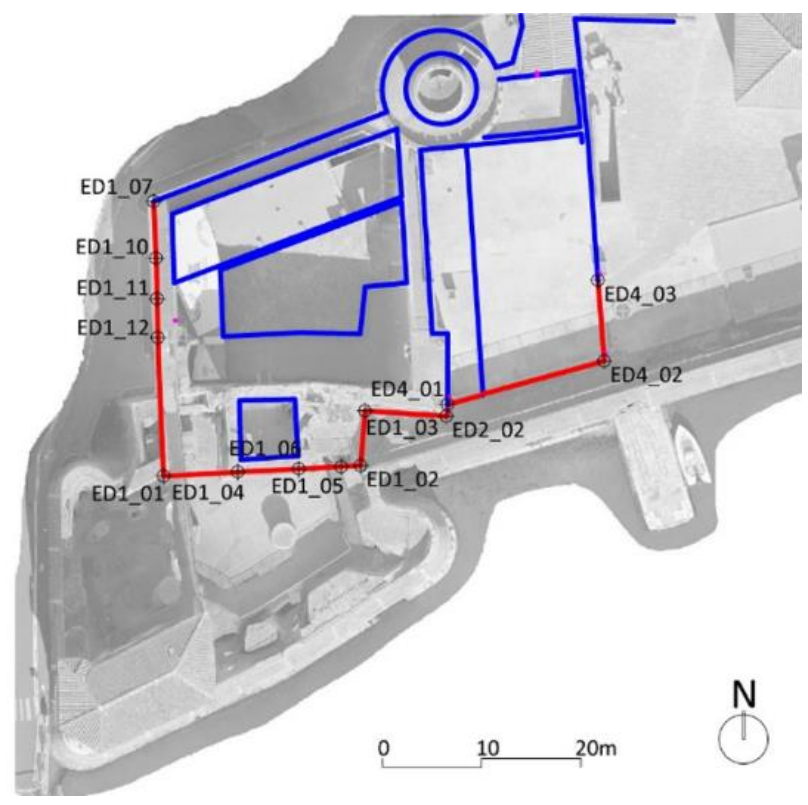

Figure 7. UAV-borne orthophotograph overlaid with the plan of the Palazzo di Cosimo de' Medici. point cloud of the status quo model in Revit. A local reference system was also created, as per Revit requirements, based on the WGS84 reference system of the photogrammetry model. This step enabled the use of Autodesk's AutoCAD software to trace the plans of the three levels of the building, which were previously processed in QGIS as stated in 3.2.1. Next, in Revit, the point cloud model provided the basis for the reconstruction of the first level of the building, corresponding to the ground level plan of the Palazzo. In order to retrieve the elevation information for the other levels, horizontal sections of the point cloud were checked against 3D points detected on historic images. Upon calculation of the height of the different levels, these were defined in Revit and the matching plans were imported. This information was fed into Revit to reconstruct the walls.

The next step involved windows and roofs. While the 2D positions of the windows were extracted from the historical plans, assessing their height required photogrammetric information. Using Revit, different window families and sizes were then defined for each window type. To reconstruct the roofs, the slope was defined by detecting relevant points on historical images, which also supplied visual clues as to the roof type, e.g. gable or hip roofs.

BIM modelling also takes the building materials into consideration, but in this case, the poor quality of the historic images prevented the determination of this information. However, future integrations involving different areas of expertise such as archaeology or architectural history could be undertaken to address this question.

Any ambiguous or illegible information was filtered out of the modelling process. Only sources that effectively cleared a given reliability threshold were used in the generation of the BIM model.

\section{CONCLUSIONS}

TLS is a well-established surveying methodology that provides an effective means of representing historical and architectural heritage items. A simple comparison between TLS surveys carried out at a 9-year interval highlights the powerful evolution this technology has undergone in this time span.

The new approach to photogrammetry based on SfM and MVS algorithms has led to major changes in the field of geomatics, as it is possible to collect high-density colour 3D point clouds that are quite similar in size to those obtained using TLS. It is, however, obvious that the achievement of such results requires adherence to specific guidelines when planning and performing the photographic shoots.

Historic images, including those that predate any changes or those from archives, can provide important information for either the 3D reconstruction of lost architectural volumes or the achievement of a fuller understanding of the status of a building during a specific period. It is not usually possible to automatically generate point clouds for the survey objects during the photogrammetric processing of these images, particularly for images with lower quality and poorer geometry. Even when this is possible, homogeneous geometric accuracy is not ensured. With regard to the Fortezza Vecchia, further processing yielded geometric information that, although it was not always sufficient for a full 3D reconstruction, did provide some references for the subsequent integration of other iconography. In the case of Porta San Zeno, which had a more consistent, natively digital image set, a 3D model was generated, providing a more detailed 

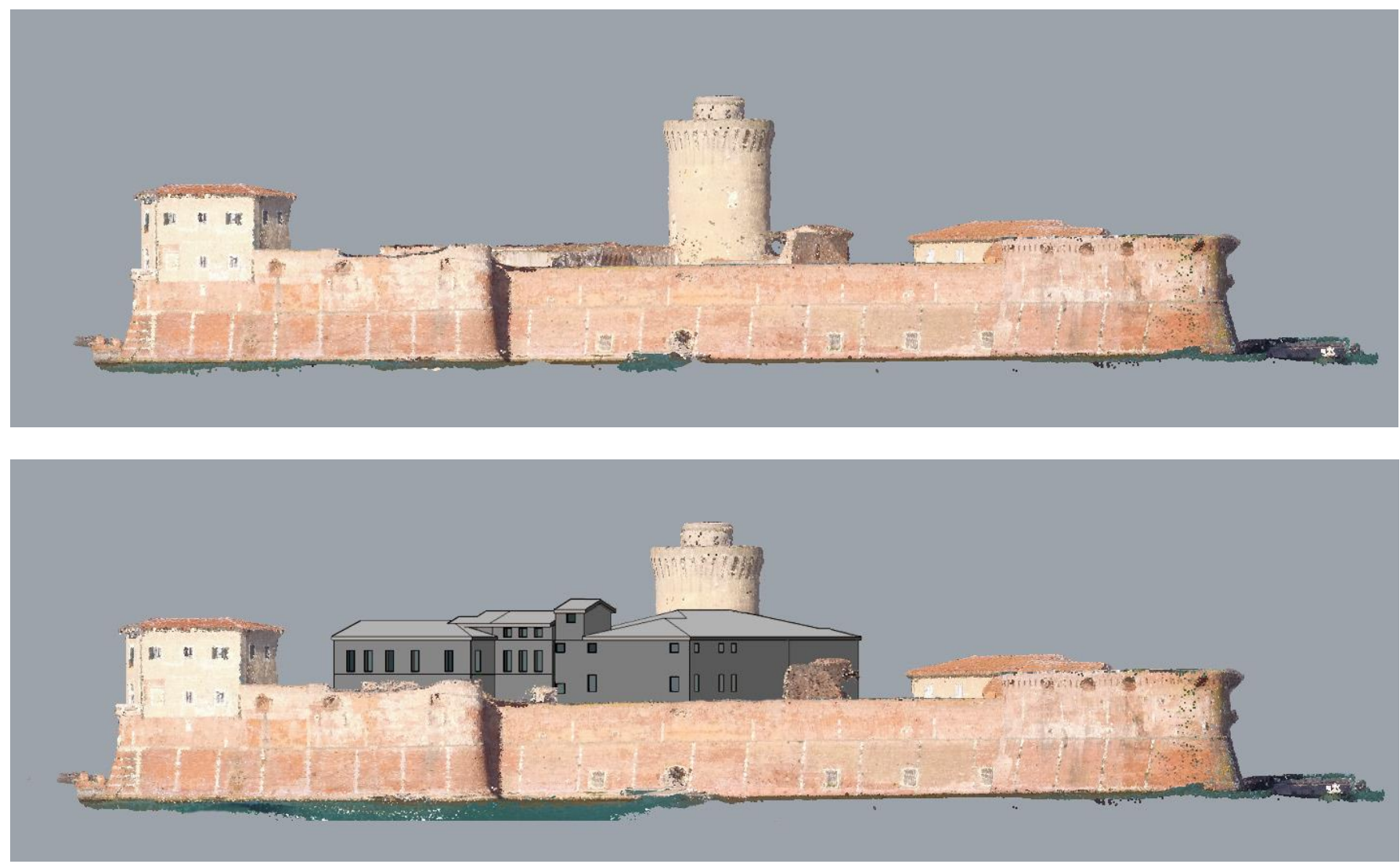

Figure 8. Virtual 3D model with and without the Palazzo di Cosimo reconstruction.

documentation of the pre-restoration status quo. In both cases, the methodology shows great potential for the expanded documentation of historical architectural objects.

$3 \mathrm{D}$ survey products are in ever-rising demand among the managers of built heritage. In this context, the ability to recover data surveyed in the past in view of the generation of $3 \mathrm{D}$ models is of the highest importance. The final models could be integrated with the status quo model by means of photogrammetric tie points for possible fruition on VR/AR platforms.

\section{ACKNOWLEDGEMENTS}

Financial support from the University of Pisa under programme PRA 2017, project 'Architetture toscane rinascimentali: casi studio fra indagine storica, rilievo e analisi strutturale' is gratefully acknowledged.

The collaboration of the Port System Authority of the Northern Tyrrhenian Sea is gratefully acknowledged.

\section{REFERENCES}

[1] B. K. Means, 3D recording, documentation and management of cultural heritage, Hist. Archaeol. 51 (2017) pp. 582-583. DOI: $10.1007 / \mathrm{s} 41636-017-0055-\mathrm{x}$

[2] P. Grussenmeyer, O. Al Khalil, From metric image archives to point cloud reconstruction: case study of the great mosque of Aleppo in Syria, ISPRS - Int. Arch. Photogramm. Remote Sens. Spat. Inf. Sci. XLII-2/W5 (2017) pp. 295-301.

DOI: 10.5194/isprs-archives-XLII-2-W5-295-2017

[3] M. G. Bevilacqua, G. Caroti, I. Martínez-Espejo Zaragoza, A. Piemonte, Orientation of archive images on 3D digital models of painted vaults: an interesting tool for restorers, Appl. Geomatics
10 (2018) pp. $385-398$

DOI: $10.1007 / \mathrm{s} 12518-018-0212-8$

[4] M. G. Bevilacqua, G. Caroti, A. Piemonte, D. Ulivieri, Reconstruction of lost architectural volumes by integration of photogrammetry from archive imagery with $3 \mathrm{D}$ models of the status quo, ISPRS - Int. Arch. Photogramm. Remote Sens. Spat. Inf. Sci. XLII-2/W9 (2019) pp. 119-125.

DOI: $10.5194 /$ isprs-archives-XLII-2-W9-119-2019

[5] G. Bitelli, M. Dellapasqua, V. A. Girelli, S. Sbaraglia, M. A. Tinia, Historical photogrammetry and terrestrial laser scanning for the 3D virtual reconstruction of destroyed structures: a case study in Italy, ISPRS - Int. Arch. Photogramm. Remote Sens. Spat. Inf. Sci. XLII-5/W1 (2017) pp. 113-119.

DOI: 10.5194/isprs-archives-XLII-5-W1-113-2017

[6] G. Bitelli, V. Girelli, M. Marziali, A. Zanutta, Use of historical images for the documentation and the metrical study of cultural heritage by means of digital photogrammetric techniques, ISPRS Arch. XXXVI-5/C5 (2007) p. 6.

[7] A. Grun, F. Remondino, L. Zhang, Photogrammetric reconstruction of the Great Buddha of Bamiyan, Afghanistan, Photogramm. Rec. 19 (2004) pp. 177-199.

DOI: $10.1111 / \mathrm{j} .0031-868 \mathrm{X} .2004 .00278 . \mathrm{x}$

[8] F. Maiwald, T. Vietze, D. Schneider, F. Henze, S. Münster, F. Niebling, Photogrammetric analysis of historical image repositories for virtual reconstruction in the field of digital humanities, ISPRS - Int. Arch. Photogramm. Remote Sens. Spat. Inf. Sci. XLII-2/W3 (2017) pp. 447-452.

DOI: $10.5194 /$ isprs-archives-XLII-2-W3-447-2017

[9] A. Cardaci, G. M. Roberti, A. Versaci, From the continuous to the discrete model: a laser scanning application to conservation projects, ISPRS - Int. Arch. Photogramm. Remote Sens. Spat. Inf. Sci. XXXVIII-5 (2012) pp. 437-444.

DOI: 10.5194/isprsarchives-XXXVIII-5-W16-437-2011

[10] G. Caroti, I. Martínez-Espejo Zaragoza, A. Piemonte, Range and image based modelling: a way for frescoed vault texturing 
optimization, ISPRS - Int. Arch. Photogramm. Remote Sens. Spat. Inf. Sci. XL-5/W4 (2015) pp. 285-290.

DOI: $10.5194 /$ isprsarchives-XL-5-W4-285-2015

[11] M. Bevilacqua, G. Caroti, I. Martínez-Espejo Zaragoza, A. Piemonte, Frescoed vaults: accuracy controlled simplified methodology for planar development of three-dimensional textured models, Remote Sens. 8 (2016) p. 239. DOI: $10.3390 / \mathrm{rs} 8030239$

[12] M. C. Spreafico, L. Perotti, F. Cervi, M. Bacenetti, G. Bitelli, V. A. Girelli, E. Mandanici, M. A. Tini, L. Borgatti, Terrestrial remote sensing techniques to complement conventional geomechanical surveys for the assessment of landslide hazard: the San Leo case study (Italy), Eur. J. Remote Sens. 48 (2015) pp. 639-660. DOI: $10.5721 / \mathrm{EuJRS} 20154835$
[13] A. Zampieri (editor), Le Mura di Pisa. Percorsi, Pacini Editore, Pisa, 2014, ISBN-10: 8863157731.

[14] D. Ulivieri, Fortezza Vecchia in Livorno, Nexus Netw. J. 16 (2014) pp. 675-697.

DOI: $10.1007 / \mathrm{s} 00004-014-0203-y$

[15] VV. AA., Livorno: Progetto e Storia di una Città tra il 1500 e il 1600, Nistri-Lischi e Pacini, Pisa, 1980.

[16] G. Piancastelli, P. Nencini, La Fortezza Vecchia: Difesa e Simbolo della Città di Livorno, Silvana Editoriale, Milano, 1995.

[17] A. Wiedemann, M. Hemmleb, J. Albertz, Reconstruction of historical buildings based on images from the Meydenbauer archives, Int. Arch. Photogramm. Remote Sens. XXXIII-P (2000) pp. 887-893. 